\title{
Modelling community vulnerability to fires using socio-economic indexes
}

\author{
M. P. Dawson \& S. A. Morris \\ South Australian Fire and Emergency Services Commission, Australia
}

\begin{abstract}
The Australian Bureau of Statistics' (ABS) 2001 Socio-Economic Indexes for Areas (SEIFA) showed strong relationships with fire-related deaths (Australia) and injuries (South Australia), being good predictors of community vulnerability to fire. The SEIFA 2001 Index of Economic Resources showed the best discrimination of vulnerability, with the fire death and injury rates of the most disadvantaged areas being 3.6 (Australia) and 2.6 (South Australia) times that of the least disadvantaged areas respectively.
\end{abstract}

Keywords: community vulnerability, fire, death, injury, risk management, SEIFA, socio-economic index.

\section{Introduction}

Australia's Council of Australian Governments has agreed fire-related deaths and injuries are national outcomes indicators [19]. Our research explores the utility of socio-economic indicators in providing insights into causal factors of these measures.

Research shows socially-disadvantaged communities have a higher incidence of structure fires and fire-related death and severe injury (Anon [2]). In New Zealand, rates of fatalities in dwelling fires in the most deprived decile were 4.5 times the rates in the least deprived decile (Duncanson et al. [16]).

We used SEIFA Indexes that ABS constructed from the 2001 Census of Population and Housing using a theoretical model that starts with core variables representing socio-economic status. Most of the disadvantage or deprivation scores used throughout the world use education, employment and income. SEIFA includes these measures and is the only score that summarises disadvantage in Australia. 
SEIFA's 'first level' variables are Education, Income and Occupation. The 'second level' variables measure aspects of disadvantage using factors like wealth, living conditions, and access to services. The 'third level' variables are those that are often associated with and/or signal disadvantage generally, rather than a specific aspect of disadvantage, such as a high percentage of Indigenous people in an area.

We first summarise fire-related deaths for Australia/South Australia to set the context for our analyses then present the first known analyses of the relationship between SEIFA 2001 and Australia's fire-related deaths and South Australia's (SA's) fire-related injuries.

\section{Data and methods}

Since ABS's most recent SEIFA indexes were for 2001 we obtained fire-related death and injury data that straddled 2001. We examined the relationship between SEIFA and fire-related variables at the Statistical Local Area (ABS [8]) level, since this the level that data for fire-related deaths and injuries is provided.

\subsection{Mortality data}

Mortality-related data for deaths that occurred in Australia are supplied to ABS by State/Territory Registrars of Birth, Death \& Marriage. Our wider research on fire-related death and injury used national fire mortality data (1979-2004) provided by ABS where Cause of Death or Underlying Cause of Death was coded as fire related. We used the 1997-2004 data for the SEIFA analyses, namely: 1,094 deaths (Australia) and 113 deaths (SA).

The data elements Cause of Death and Underlying Cause of Death are coded to the World Health Organisation's (WHO) International Classification of Diseases (ICD) [19]. Since 1997 these elements have been coded to version 10 (ICD-10). The following ICD10 codes were used: Total Fire Deaths (x00-x09, x76, x97, y26), Accidental Fire Deaths (x00-x09, y26) and Intentional Fire Deaths (x76, x97).

\subsection{Injury data}

The South Australian Department of Health supplied hospital separation data from public and private hospitals for people treated for fire-related injuries between 1997-2003. There were 1,892 hospitalisations in South Australia identified as fire-related external cause during this period. Analyses were conducted using data for 1,742 SA residents hospitalised for fire injury.

\subsection{SEIFA 2001 and fire death \& injury rates}

ABS used principal component analyses $[9,10]$ to calculate four SEIFA indexes using data from the 2001 Census (higher scores represent greater disadvantage).

\subsubsection{Index of relative socio-economic advantage/disadvantage}

The model uses 31 variables, grouped as income, education, occupation and use of the internet at home. 


\subsubsection{Index of relative socio-economic disadvantage}

The model uses 20 variables, grouped as low income, low education, low occupation, household renting from government, marital status, indigenous status, lacking fluency in English, unemployment and high-occupancy dwelling.

\subsubsection{Index of economic resources}

The model uses 15 variables, grouped as income, rent payment, mortgage payment and dwelling with four or more bedrooms.

\subsubsection{Index of education and occupation}

The model uses 17 variables, grouped as education and occupation.

The 2001 SEIFA indexes for 1,334 SLAs in Australia were obtained from the ABS website [11]. For each index, the SLAs were ranked lowest to highest then divided into deciles.

The population of each decile was summed then per capita rates of deaths and injuries were calculated. The international conventions of Fire Deaths per Million Population (FDPM) and Fire Injuries per Million Population (FIPM) were used, being population-standardised using ABS [14]. For Figure 1, data were smoothed using a three-year centred moving average.

\section{Results}

\subsection{Three-year death rate comparison - Australia, USA \& UK}

Figure 1 shows Australian FDPM peaked with the Ash Wednesday bushfire deaths in 1983 but is below that of the USA and the UK, flattening for the year

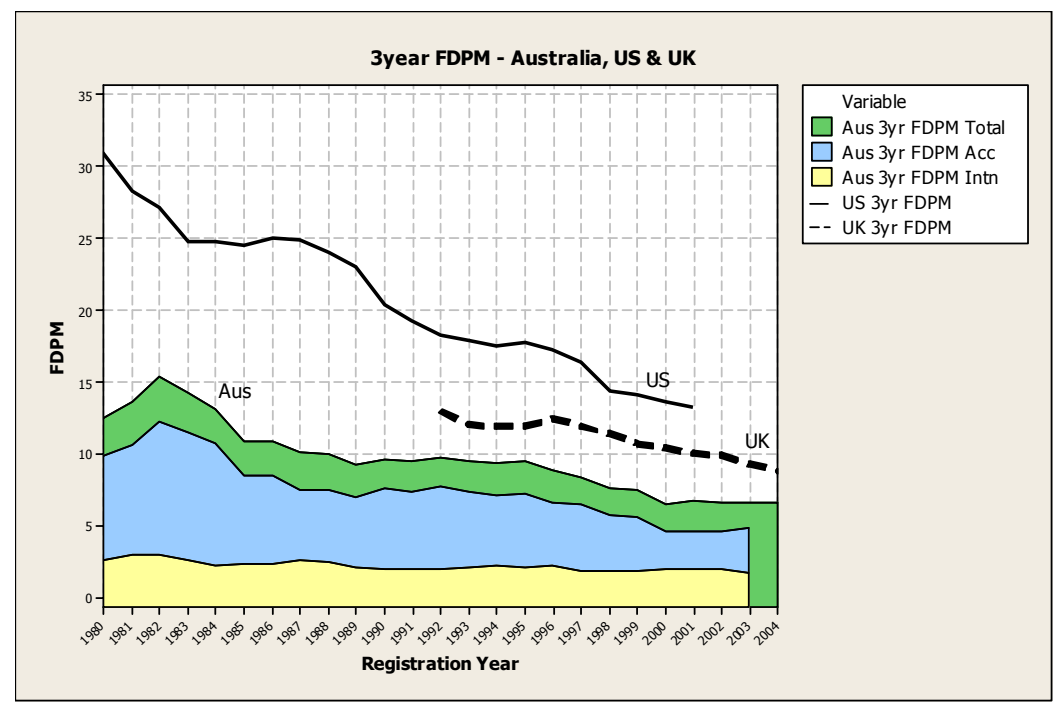

Figure 1: Fire death rate trends: Australia, USA, United Kingdom (ABS [13], Hall [17], Anon [6]). 
2000 with an apparent marginal increase thereafter. In contrast, the UK death rate continued to drop. Australia's intentional death (homicide, suicide) rate appears stable, but the accidental death rate may be increasing slightly to 2004 .

\subsection{Fire-related deaths (AUS 1997-2004) and injuries (SA 1997-2003)}

Figure 2 shows Australian and South Australian fire death rates, with intentional deaths (homicide, suicide) segregated from total deaths. Approximately $75 \%$ of fire-related deaths were recorded as accidental, with the remaining $25 \%$ classified as intentional self harm or assault by smoke, fire and flames.

Nationally, males and females comprised $61 \%$ and $39 \%$ respectively of the total, accidental and intentional fire deaths, similar to South Australia's 64\% and $36 \%$.

For South Australia, on average there were 249 fire-related injuries and 13.8 fire-related deaths per year (i.e. injuries were approximately 18 times deaths) with 12.5 accidental and 4.1 intentional fire-related deaths per year. Males comprised $72.6 \%$ of fire injuries.

SA recorded its largest number (42) of fire-related deaths in 1983. SA's accidental FDPM dropped after the Ash Wednesday fires before rising steadily from 1987 (6.2) to 1993 (11.2), then declining to its lowest rate (5.6) in 2004. SA's intentional fire deaths increased from 2001, compared to a marginal decrease nationally.

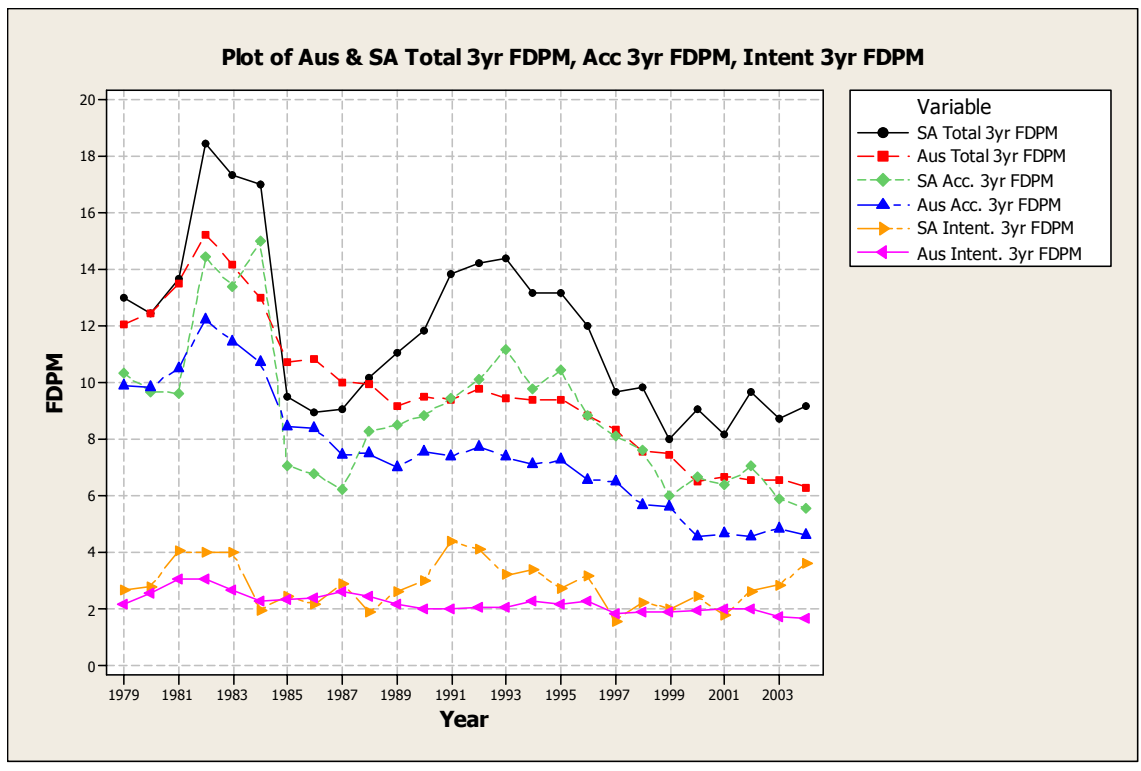

Figure 2: $\quad$ Fire death rate trends: Australia and South Australia.

Table 1 shows South Australia's highest injury rate (268.8 FIPM) was for the 00-04 age cohort, approximately 1.6 times the population rate of 165.4 FIPM. 
This group may be the most vulnerable to fire injury, since it relies on the vigilance and assistance of care givers. Older people, especially males 85+ (242.5 FIPM) may also rely heavily on care givers.

Male injury rates exceeded those of females for each age group. Male age cohorts 20-24, 25-29 and 15-19 had the highest male injury rates, compared to the highest female injury rates for ages 00-04, 30-34 and 20-24.

For females (aside from those aged 00-04) higher than average rates occurred for those aged 20-44 and 80-84.

For males (aside from those aged 00-04) higher than average rates occurred for those aged 10-44 and 85+. Males face higher fire injury risk for longer periods of life than females.

Table 1: $\quad$ SA fire-related injuries (1997-2003) by age group and gender.

\begin{tabular}{|r|r|r|r|}
\hline $\begin{array}{r}\text { Age } \\
\text { Group }\end{array}$ & \multicolumn{3}{|c|}{ FIPM } \\
\hline $\mathbf{5 y r}$ & Male & Female & Persons \\
\hline $00-04$ & 288.2 & 248.4 & 268.8 \\
\hline $05-09$ & 90.1 & 74.3 & 82.4 \\
\hline $10-14$ & 255.8 & 52.3 & 156.8 \\
\hline $15-19$ & 376.8 & 87.3 & 235.3 \\
\hline $20-24$ & 385.9 & 102.0 & 247.7 \\
\hline $25-29$ & 377.9 & 92.8 & 237.8 \\
\hline $30-34$ & 344.7 & 122.0 & 234.1 \\
\hline $35-39$ & 271.7 & 99.2 & 185.5 \\
\hline $40-44$ & 245.1 & 96.9 & 170.6 \\
\hline $45-49$ & 201.8 & 50.3 & 125.3 \\
\hline $50-54$ & 152.3 & 57.2 & 104.4 \\
\hline $55-59$ & 159.0 & 78.7 & 118.8 \\
\hline $60-64$ & 153.8 & 42.9 & 97.7 \\
\hline $65-69$ & 118.7 & 55.9 & 86.5 \\
\hline $70-74$ & 117.8 & 75.1 & 95.0 \\
\hline $75-79$ & 121.1 & 57.3 & 84.4 \\
\hline $80-84$ & 145.2 & 93.9 & 113.9 \\
\hline $85+$ & 242.5 & 82.1 & 130.7 \\
\hline & $\mathbf{2 4 3 . 0}$ & $\mathbf{8 9 . 5}$ & $\mathbf{1 6 5 . 4}$ \\
\hline & & & \\
\hline
\end{tabular}

\begin{tabular}{|c|c|c|c|c|c|}
\hline \multicolumn{3}{|c|}{ \#Injuries } & \multicolumn{3}{|c|}{$\%$ Total Injuries } \\
\hline Male & Female & Total & Male & Female & Total \\
\hline 96 & 79 & 175 & 5.5 & 4.5 & 10.0 \\
\hline 32 & 25 & 57 & 1.8 & 1.4 & 3.3 \\
\hline 93 & 18 & 111 & 5.3 & 1.0 & 6.4 \\
\hline 136 & 30 & 166 & 7.8 & 1.7 & 9.5 \\
\hline 136 & 34 & 170 & 7.8 & 2.0 & 9.8 \\
\hline 138 & 33 & 171 & 7.9 & 1.9 & 9.8 \\
\hline 132 & 46 & 178 & 7.6 & 2.6 & 10.2 \\
\hline 109 & 40 & 149 & 6.3 & 2.3 & 8.6 \\
\hline 97 & 39 & 136 & 5.6 & 2.2 & 7.8 \\
\hline 75 & 19 & 94 & 4.3 & 1.1 & 5.4 \\
\hline 53 & 20 & 73 & 3.0 & 1.1 & 4.2 \\
\hline 45 & 23 & 68 & 2.6 & 1.3 & 3.9 \\
\hline 35 & 10 & 45 & 2.0 & 0.6 & 2.6 \\
\hline 24 & 12 & 36 & 1.4 & 0.7 & 2.1 \\
\hline 22 & 16 & 38 & 1.3 & 0.9 & 2.2 \\
\hline 17 & 11 & 28 & 1.0 & 0.6 & 1.6 \\
\hline 12 & 12 & 24 & 0.7 & 0.7 & 1.4 \\
\hline 13 & 10 & 23 & 0.7 & 0.6 & 1.3 \\
\hline 1265 & 477 & 1,742 & 72.6 & 27.4 & 100.0 \\
\hline
\end{tabular}

\subsection{SEIFA 2001 and fire-related deaths and injuries}

Figure 3 shows FDPM increased with disadvantage for each SEIFA index, with the Index of Economic Resources showing the largest discrimination: 16.6 FDPM in decile 1 versus 4.6 FDPM in decile 10 (3.6 times the death rate).

For each SEIFA Index discrimination deteriorated for the least-disadvantaged deciles 8, 9 and 10 .

Similar relationships were found with FIPM and disadvantage: 293.6 FIPM in decile 1 versus 113.8 FIPM in decile 10 with the Index of Economic Resources (2.6 times the injury rate). For this index male FIPM exceeded female FIPM, with relatively more male injuries with increasing disadvantage. 

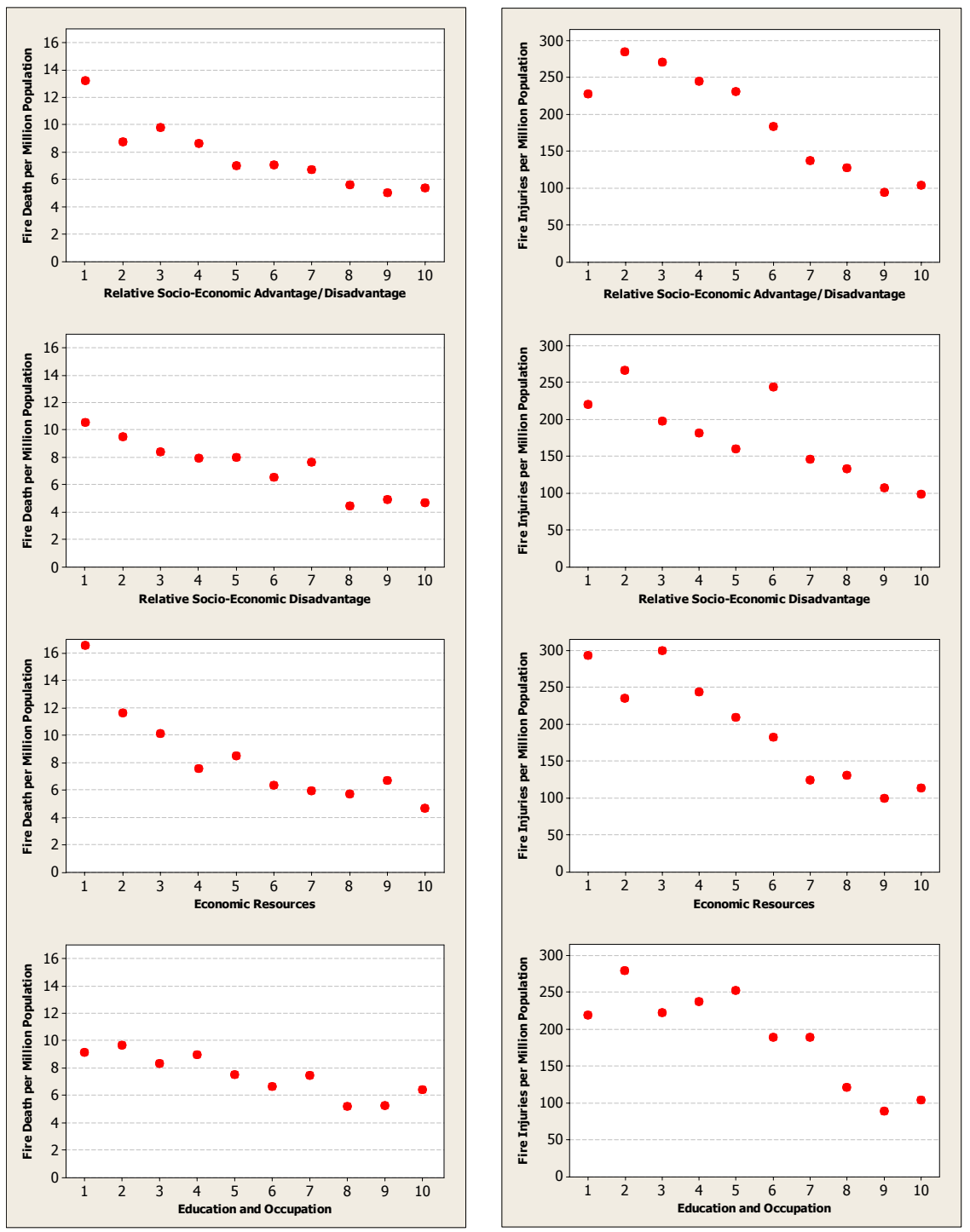

Figure 3: $\quad$ Fire death (AUS) and injury (SA) rates against SEIFA 2001.

\section{Discussion}

Australia's fire-related death rate has trended lower than that of the USA and the UK. To reduce this further we expect we'll need to better understand the factors contributing to death rate to guide our assessment of pathways for effective policy intervention. 
SEIFA and its component variables offer avenues to better insights into factors related to vulnerability to fire. Regardless of the overall strength of SEIFA's relationships with fire-related death and injury, our results clearly demonstrate a case for better understanding the sociology of the most disadvantaged areas.

South Australia's population is ageing faster than elsewhere in Australia, increasing demand for health, social and other services. By 2051 almost $31 \%$ of SA's population is projected to be over 65 and the over 85 population is expected to have increased four fold (ABS [15]). Further, SA has the oldest population with a language other than English, with around 1 in 5 people aged 65 and over born in non-English speaking countries. These people have special needs (Anon [4]) as do those with mental health issues (ABS [12]).

While SEIFA predicts areas where we need to better understand vulnerability, it is a derived, contextual variable that isn't designed to approximate individual characteristics. That is, use of Census District-level SEIFA to describe a person suffers from ecological fallacy. Similarly, aggregating SEIFA to State level suffers from atomistic fallacy (Adhikari [1]). Therefore, SEIFA provides a lens for us to drill down to the actual situation of people most vulnerable to fire, particularly those living alone or socially excluded (Anon [5]).

Community safety and other interventions will need to target our ageing population, requiring sociological and other understandings essential to successful engagement before safety intervention strategies are developed and implemented.

SA's Ageing Plan for South Australia (Anon [7]) emphasises our government's commitment to staying in front through research and information gathering to help develop new models for services that support growing old in our own homes. Two of its five areas of focus are "Providing safety, security and protection - in our homes, communities and consumers" and "Staying in front - through research, innovative practices and collaboration with others". Other service providers/caregivers may be better placed than emergency services as service channels to vulnerable groups. Emergency services may well need to identify such channels then foster partnerships to reduce vulnerability to fire and other emergencies - consistent with the Ageing Plan's philosophy of joined up action.

\section{Conclusions}

Similar to the research findings for other countries, Australia's socio-economic indices are good predictors of fire-related deaths and injuries. We're currently analysing fire deaths and injuries in relation to age and other factors within SEIFA's variables which may better explain vulnerability. The results of this work should enable our emergency services to better target their community risk treatment services to improve community safety.

Our conference presentation and subsequent papers drill into lower levels of potentially-causal factors then explain how these results have been used to better understand the sociology of vulnerable communities to ensure community 
engagement and interventions to reduce fire-related risk can be effectively planned, targeted and evaluated.

\section{Acknowledgements}

The Australian Bureau of Statistics provided deaths data under a Data Agreement with State/Territory Registrars of Birth, Death and Marriage. ABS also provided SEIFA data and advice on statistical methods.

The South Australian Department of Health supplied hospital separation data for people treated for fire-related injuries.

\section{References}

[1] Adhikari, P., Socio-Economic Indexes for Areas, Australian Bureau of Statistics, seminar notes 24 May 2006.

[2] Anon, Socioeconomic Factors and the Incidence of Fire, Federal Emergency Management Agency, United States Fire Administration, FA 170, June 1997.

[3] Anon, An NFIRS Analysis: Investigating City Characteristics and Residential Fire Fatalities, Federal Emergency Management Agency, United States Fire Administration, FA 170, April 1998.

[4] Anon, Strategic Directions for Older people from Culturally and Linguistically Diverse Backgrounds, Department of Human Services, 2002.

[5] Anon, Social Exclusion and the Risk of Fire, Arson Control Forum Research Bulletin No. 4, Office of the Deputy Prime Minister, 2004.

[6] Anon, Fire Statistics, Dept for Communities and Local Government, United Kingdom, 2005; Population, Office for National Statistics, General Register Office for Scotland, Northern Ireland Statistics and Research Agency.

[7] Anon, Improving with Age - Our Ageing Plan for South Australia, Office for the Ageing, Department of Families and Communities, 2006.

[8] Australian Bureau of Statistics, Australian Standard Geographical Classification, Cat. no. 1216.0, 2001. http://www.abs.gov.au/AUSSTATS /abs@.nsf/Lookup/1216.0Main+Features12001?OpenDocument

[9] Australian Bureau of Statistics, Information Paper: Socio-economic Indexes for Areas, Cat. no. 2039.0, 2001. http://www.abs.gov.au/AUSSTATS /abs@.nsf/allprimarymainfeatures/09D68973F50B8258CA2573F0000DA1 81?opendocument

[10] Australian Bureau of Statistics, Census of Population and Housing: SocioEconomic Indexes for Areas (SEIFA), Technical Paper, Cat. no. 2039.0.55.001, 2001. http://www.abs.gov.au/AUSSTATS/abs@.nsf /allprimarymainfeatures/84BA62790D4E5B66CA2574170011ADFB?open document

[11] Australian Bureau of Statistics, Socio-economic Indexes for Areas (SEIFA), Australia - Data Cube, Cat. no. 2033.0.55.001, 2001. 
http://www.abs.gov.au/AUSSTATS/abs@.nsf/allprimarymainfeatures/C53 F24374E92E8D3CA2573F0000DA0BE?opendocument

[12] Australian Bureau of Statistics, National Health Survey: Mental Health, Cat. No. 4811.0, 2001.

[13] Australian Bureau of Statistics, Causes of Death, Australia, Cat. no. 3303.0 (unpublished).

[14] Australian Bureau of Statistics, Australian Historical Population Statistics, Cat. no. 3105.0.65.001. Population estimates as at 30 June.

[15] Australian Bureau of Statistics, Population Projections, Australia, 20022021, 2005.

[16] Duncanson, M., Woodward, A. \& Reid, P., Social and economic deprivation and fatal unintentional domestic fire incidents in New Zealand 1988-1998. New Zealand Fire Service Commission Report Number 5, 2000.

[17] Hall, J.R. Jr., Fire in the US and Sweden, National Fire Protection Association, April 2004.

[18] Productivity Commission, Report on Government Services 2008 http://www.pc.gov.au/gsp/reports/rogs/2008/emergencymanagement

[19] World Health Organisation, International Classification of Diseases, http://www.who.int/classifications/icd/en/ 